\title{
ERJ
}

Engineering Research Journal

Faculty of Engineering

Mínoufiya University

\section{FINITE ELEMENT ANALYSIS OF PRESTRESSED STEEL BEAMS}

\author{
Ahmed Almohamady \\ Construction Department, Faculty of Engineering, \\ Misr University for Science and Technology (MUST), Cairo, Egypt.
}

\begin{abstract}
The concept of prestressing steel structures has only recently been widely considered, despite a long and successful history of prestressing concrete members. The configuration of the beam affects the straining actions and deformations of the prestressed steel beams.

In this research, the behavior of the prestressed steel beams is illustrated using finite element analysis. The dimensions of the beam have been changed to find out their effect. The existence of vertical stiffeners has been also studied to find out its influence on prestressed steel beams compared with non-prestressed beams. This study has been carried out under the same static loads. The results show that it is better to increase the flange width to improve the stiffness of the prestressed beams while it is better to increase the web depth to improve the stiffness of the nonprestressed beams. It has been also noticed that there is not any obvious benefits of using vertical stiffeners.

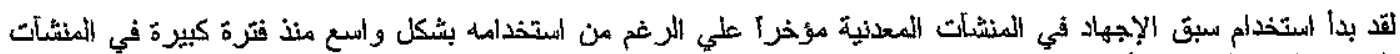

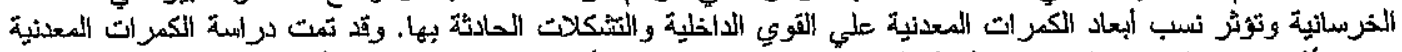

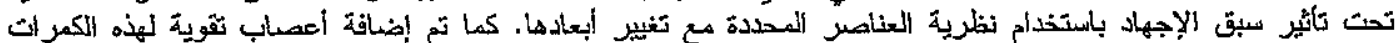

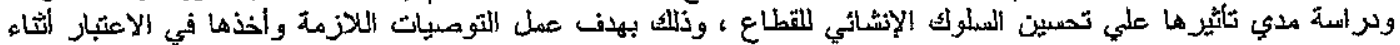
التصميم الإنثائي.
\end{abstract}

Keywords: Pre-stressed, Stiffeners, Finite Element Analysis (FEA), Steel beams

\section{INTRODUCTION}

The main reason of why pre-stressed steel structures are infrequently erected are due to a lack of knowledge regarding the system and the calculation methods. Once this information becomes general knowledge within the scientific and the construction community, there will be the same rapid adoption of prestressed steel (P.S.) technology as there was for similar technologies, for example, prestressed concrete (P.C.). In this respect, prestressed steel technology is the new frontier for structural engineering. The aim of this paper is to present a static analysis of significant prestressed steel structures, together with relevant results, and to compare them with other structural typologies [1].

\section{ANALYSIS OF PRE-STRESSED STEEL STRUCTURES}

A prestressed system consists quite simply in "subjecting a structure to loads that produce opposing stresses to those when it is in service". Prestressing can be usefully applied to any material and, in particular to steel (figure 1), thus improving considerably its resistance characteristics. In the case of P.C., the effect of prestressing enables beams to pass from being partial reagents to becoming total reagents (only compression), (figure 2 ). The increase in the characteristics of resistance is solely due to a greater use of the section. In the case of steel this is taken for granted [2].

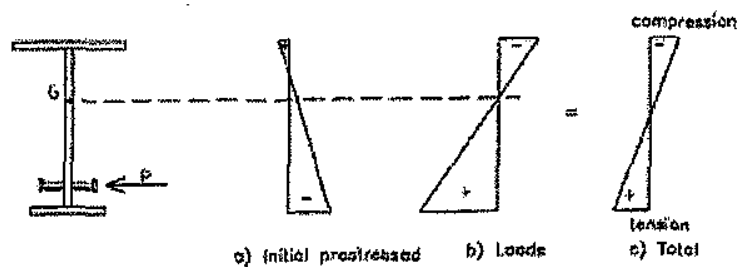

Figure (1), Prestressed steel girder.

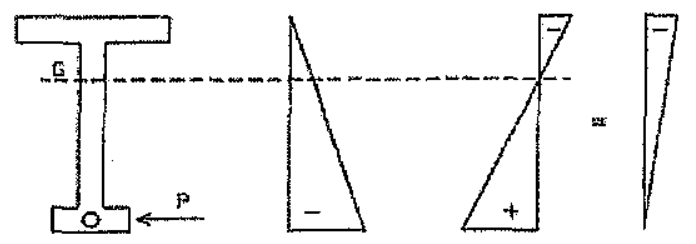
a) Prestressed
b) prestresand
c) loads
d) totat

Figure (2), Prestressed concrete beam.

The methods used for analyzing the sections are:

- The static method, in which at each section the effect of prestressing is considered as an eccentric pressure (traditional method).

- The equivalent loads method, in which the effect of prestressing is analyzed through the introduction of 
a system. of equivalent forces of external provenance which exert pressure upon the girder. These pressures are called "equivalent loads".

\section{STATIC ANALYSIS OF THE SECTYON}

With reference to a simply supported prestressed steel beam, it will be necessary to assess in the highly stressed section whether, the tensions owing to the loads and the prestressing are lower than those allowed for by the limit state under consideration or not. An admissible value for tension loss for P.S., on account of friction and steel relaxation is $5 \%$. The value of the tension losses that is considered in this research is $10 \%$ (generally for P.C., tension losses due to friction, creep shrinkage etc. are presumed to be $25 \%-30 \%$ ). Two load conditions will be taken into account, more precisely, an initial or "at transfer" condition and a final or "at service" condition. In the first case the prestressing force $P$ will be increased through the application of a coefficient $\beta=1.10$ to take account of the total (or final) tension loss [3].

\section{FINITE ELEMENT MODEL}

The finite element method, sometimes referred to as finite element analysis, is a computational technique used to obtain approximate solutions of boundary value problems in engineering. The boundary conditions are the specified values of the field variables (or related variables such as derivatives) on the boundaries of the field. Depending on the type of physical problem being analyzed (3). SOLID45 is used for the three-dimensional modeling of solid structures. The element is defined by eight nodes having three degrees of freedom at each node: translations in the nodal $x, y$, and $z$ directions. The element has plasticity, creep, swelling, stress stiffening, large deflection, and large strain capabilities.

\subsection{Input Data}

The geometry, node locations, and the coordinate system for this element are shown in Figure (3). The element is defined by eight nodes and the orthotropic material properties. Orthotropic material directions correspond to the element coordinate directions. Element loads and pressures which may be input as surface loads on the element faces as shown by the circled numbers in Figure (3) Positive pressures act into the element.

\subsection{Output Data}

The solution output associated with the element is in the form of nodal displacements included in the overall nodal solution. Several items are illustrated in Figure (4). The element stress directions are parallel to the element coordinate system. The surface stress outputs are in the surface coordinate systems and are available for any face. The coordinate systems for faces IJNM and KLPO are shown in Figure 2. The other surface coordinate systems follow similar orientations as indicated by the pressure face node description.
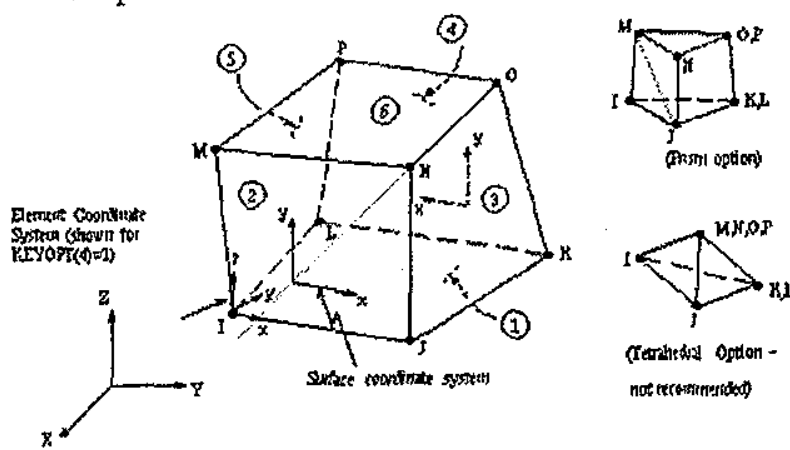

(Terilatal Opton

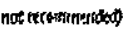

Figure (3) Solid 45 3-D structural solid.

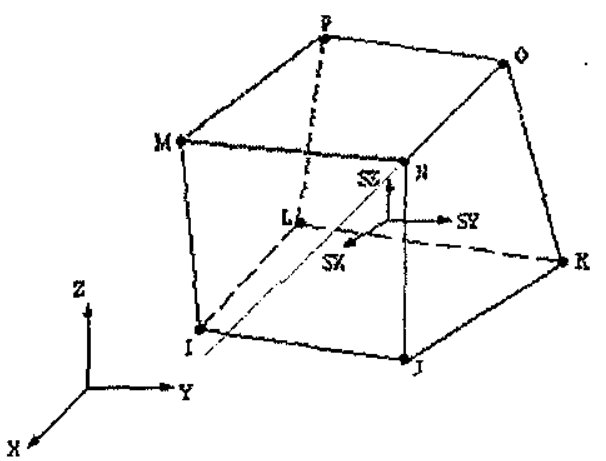

Figure (4) Solid 45 Stress Output.

\section{NON-LINEAR ANALYSIS}

Material non-linearity occurs when the stress-strain relationship stops to be linear and the steel yields and becomes plastic. The three sets of material data were as follows: For the elastic data the all elements were defined as elastic isotropic with a Young's Modulus of Elasticity of $2.05 \times 10^{3} \mathrm{t} / \mathrm{cm}^{2}$ and Poisson's lateral to longitudinal strain ratio of 0.3 .

The prestressed beams have been modeled to study thier behavior at difference dimensions of web depth and flange width under the influence of adding vertical stiffeners. A disturbance force had been added to the system in order to actuate the structure to buckling. To study the behavior of structure, six cases have been modeled as the following:

$\times$ Case I: Prestressed steel beams with vertical stiffeners.

$\times$ Case II: Prestressed steel beams without vertical stiffeners.

$\times$ Case III: Prestressed steel beams with vertical stiffeners under doubling vertical loads.

$\times$ Case IV: Steel beams with vertical stiffeners.

$x$ Case V: Steel beams without vertical stiffeners.

$\times$ Case VI: Steel beams with vertical stiffeners under doubling vertical loads. 
The shape of finite element modeling of the prestressed beams is shown in figure (5). The beam has been loaded with a distributed load to study the resulting stresses and deformations, also the maximum deflection. The dimension of modeled beams has been changed as shown in Table (1) to make a parameter study for the given model.

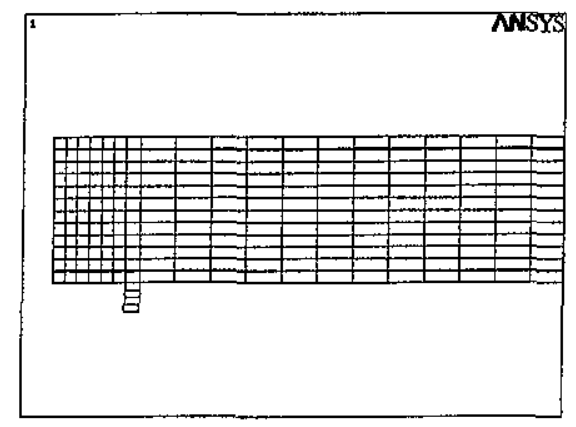

a) Steel Beams

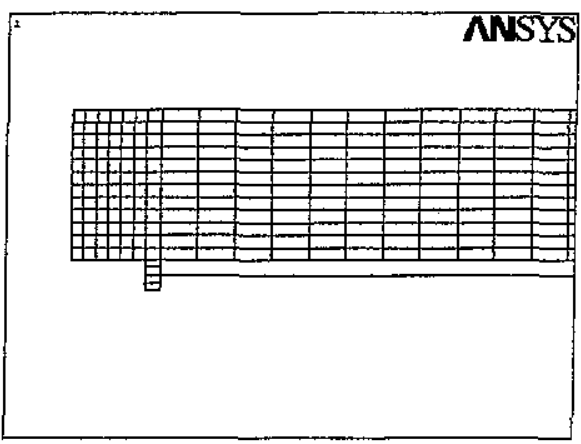

b) Prestressed Steel Beams

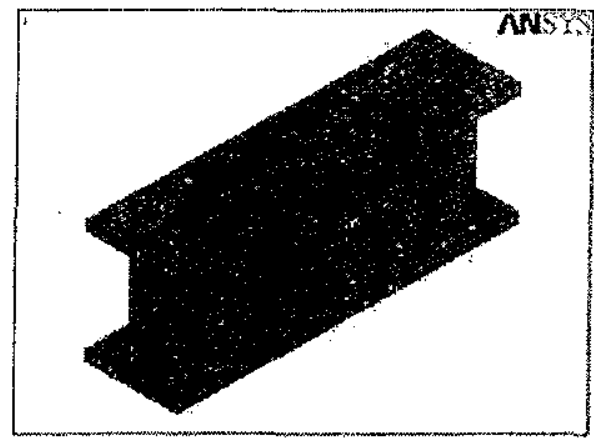

c) Beams without stiffeners

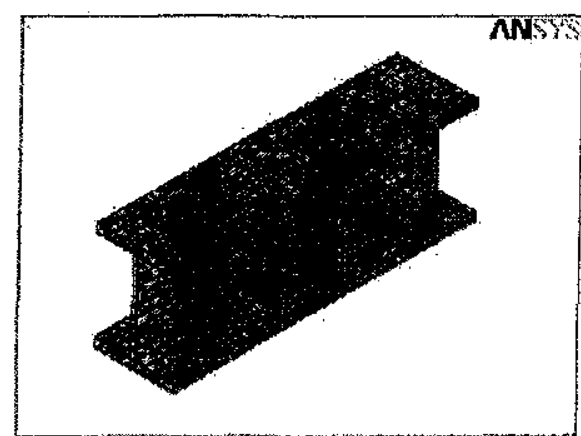

d) Beams with stiffeners

Figure (5) Finite element models
Table (1) Beam dimensions

\begin{tabular}{|c|c|c|c|c|c|}
\hline 16 & and & Whe & tiong & 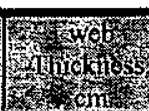 & (4) \\
\hline 1 & 20 & 10 & \multirow{6}{*}{1.6} & \multirow{6}{*}{0.80} & \multirow{6}{*}{1.6} \\
\hline 2 & 25 & 10 & & & \\
\hline 3 & 30 & 10 & & & \\
\hline 4 & 35 & 10 & & & \\
\hline 5 & 20 & 15 & & & \\
\hline 6 & 20 & 20 & & & \\
\hline
\end{tabular}

\section{ANALYSIS AND DISCUSSION}

The stresses of the given models have been studied at specified values of loads as illustrated in figure (6) for the four cases. Cases (II) and (V) have been chosen as reference to compare these results in the variable cases with their results.

Table (2) gives the results of stresses and deformations for the six cases. For each case it can be noted that increasing in web depth at constant flange width leads to increasing in tension stresses in top flange with increasing in compression stress in bottom flange and decreasing in deflection. In the other hand increasing in flange width at constant web depth leads to decreasing in compression stresses in top flange with decreasing in tension stress in bottom flange and decreasing in deflection.

In addition, from the same table it can be noted that increasing the web depth at constant flange width leads to decreasing the compression stresses in top flange with decreasing the tension stress in bottom flange and decreasing the deflection. In the other hand increasing the flange width at constant web depth leads to decreasing the compression stresses in top flange with decreasing in tension stress in bottom flange and decreasing in deflection.

The results of tension and compression stresses at mid span of finite element model are shown in figure (6) the figure illustrates for each case the effect of using stiffeners in the two conditions of beams without prestressing and prestressed beams.

The relationship between top flange stresses (Sx) and web depth to flange width ratio at constant web depth was examined and illustrated in figure (7) from this figure, it can be noted that increasing in web to flange ratio attends to increasing the compression stresses in top flange. In addition using stiffeners leads to increasing the compression stresses by approximately $20 \%$ in case of beams without prestressing and prestressed beams. In the other hand increasing in web to flange ratio at constant flange width leads to increasing in compression stresses (Sx) in top flange as illustrated in figure (8). In additional in case of using stiffeners leads to increasing in tension and compression stress by approximately $20 \%$ in each case of beams without prestressing and prestressed beams. 


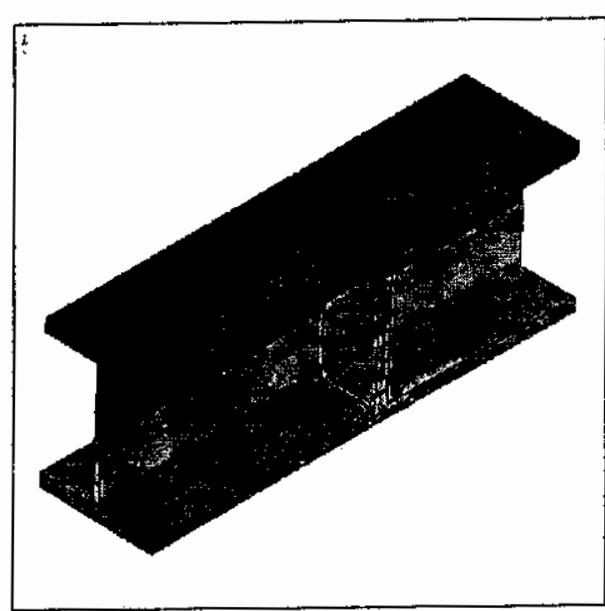

a) Case I

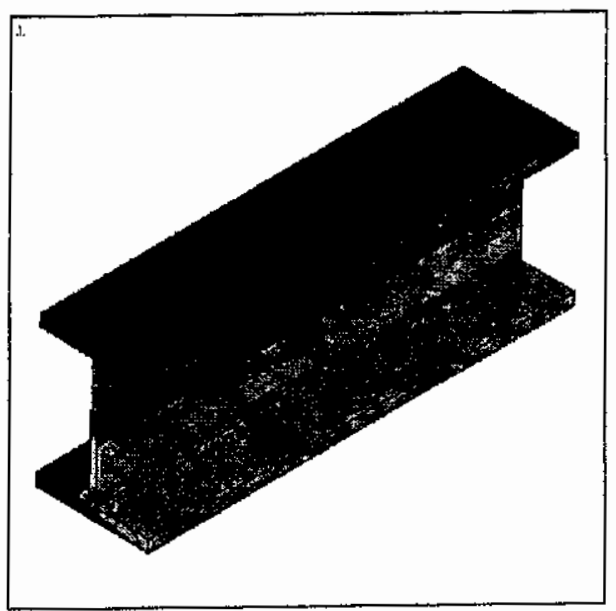

b) Case II

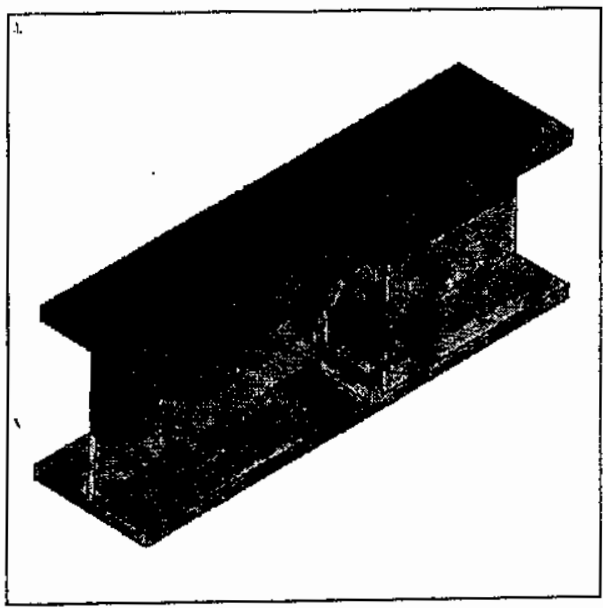

c) Case III

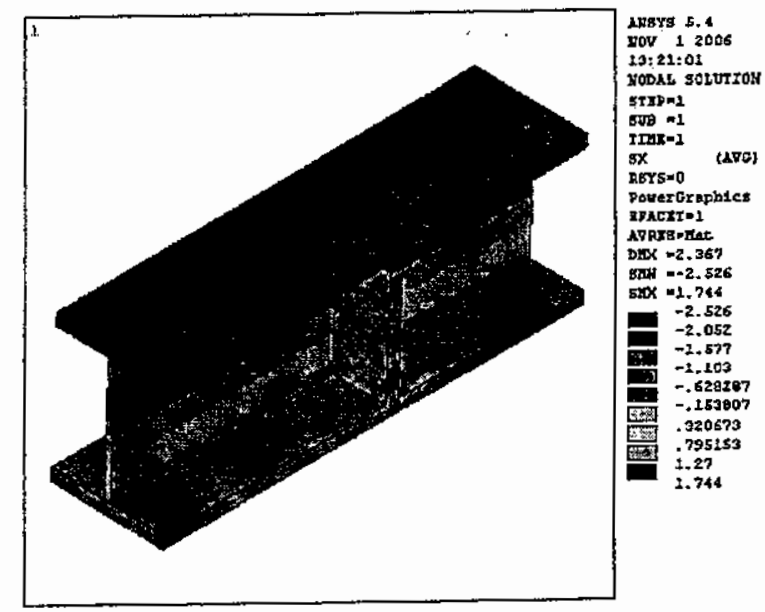

d) Case IV

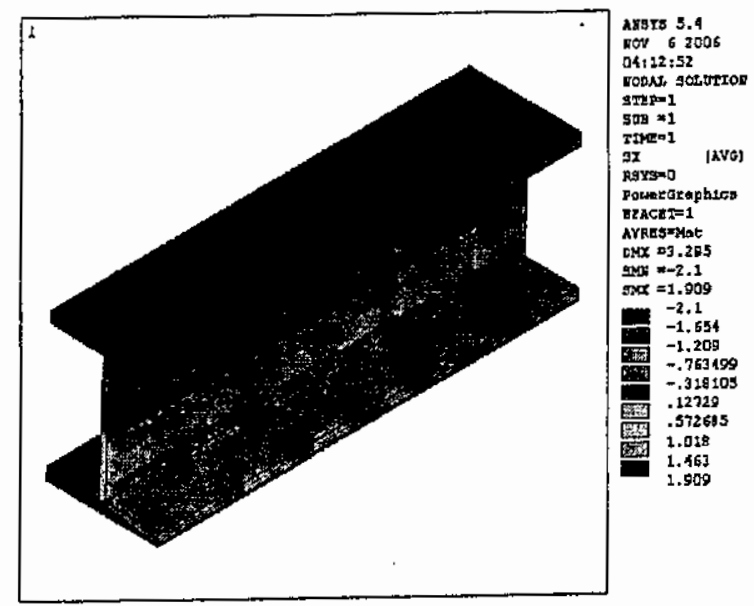

e) Case V

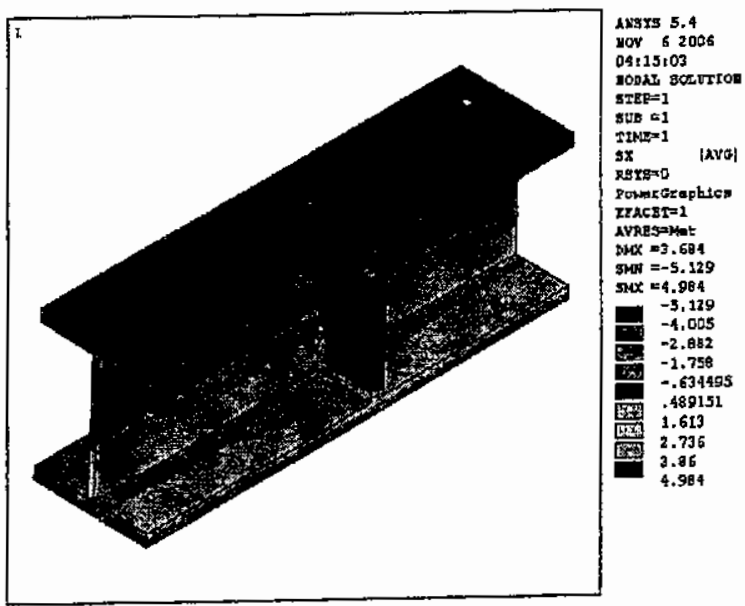

f) Case VI

Figure (6) Tension and compression stresses (Web depth $=20 \mathrm{~cm}$ and flange width $=15 \mathrm{~cm}$ ) 
Table (2) Results of stresses and deformations

\begin{tabular}{|c|c|c|c|c|c|}
\hline \multicolumn{6}{|c|}{ Case I } \\
\hline & \multicolumn{2}{|c|}{$\begin{array}{c}\text { Top stuess, } \\
\text { dism }\end{array}$} & \multicolumn{2}{|c|}{$\begin{array}{c}\text { Boftom stress } \\
\text { t/ent? }\end{array}$} & \multirow{2}{*}{$\begin{array}{c}\text { Deflection } \\
, \mathrm{nmm}\end{array}$} \\
\hline & S.x & $\mathrm{Sz}$ & $5 x$ & $S_{i}$ & \\
\hline $\mathrm{T}-\mathrm{l}$ & -5.9117 & 0.0538 & 4.2354 & .0 .1143 & -3.6076 \\
\hline 1.2 & 0.0712 & 0.0024 & $-(0.6959$ & 0.0162 & $0.2+63$ \\
\hline 3.3 & $0,086 ?$ & .0 .0028 & 0.6700 & 0.0163 & 0.2008 \\
\hline 1.4 & 0,0273 & -0.0081 & -0.6596 & 90161 & 0.1674 \\
\hline $1-5$ & -20481 & $1.19+5$ & $1+494$ & 0.6514 & -1.1765 \\
\hline 1.6 & $-1,114$ & 0.6600 & 1.3006 & -0.0515 & $-0,0336$ \\
\hline \multicolumn{6}{|c|}{ CustelI } \\
\hline & \multicolumn{2}{|c|}{$\begin{array}{l}\text { Top sfress. } \\
\text { tcme }\end{array}$} & \multicolumn{2}{|c|}{$\begin{array}{c}\text { Botlom stress, } \\
\text { lím2 }\end{array}$} & \multirow{2}{*}{$\begin{array}{l}\text { Deflection } \\
\text {,mm }\end{array}$} \\
\hline & $5 x$ & $5 \%$ & $5 x$ & $5 x$ & \\
\hline IIII & 4.877 & -5.921 .02 & 4.016 & $-9,26 \mathrm{P}-0$. & .7624 \\
\hline $\mathrm{H}-2$ & 0.081 & $+3.9 \mathrm{SOE}, 05$ & -0.537 & $445 E-05$ & 0,248 \\
\hline 11-3 & 0.032 & $-4,+3 E-05$ & $-0,515$ & $50(1 \mathrm{E}-0 S$ & 0.202 \\
\hline $11-4$ & 0,098 & $-4.85 E \cdot 05$ & .0 .493 & $409 \mathrm{E} \times 05$ & 13.163 \\
\hline 1165 & .1666 & $-5,322 \mathrm{E} \cdot 02$ & 1,210 & $-3.22 \mathrm{E}-172$ & -1.181 \\
\hline ][-6 & +256 & 0.11808 & 0,933 & $-7.981 \div 02$ & -0.229 \\
\hline \multicolumn{6}{|c|}{ Case III } \\
\hline & \multicolumn{2}{|c|}{$\begin{array}{l}\text { Top stress, } \\
\text { ucm } 2\end{array}$} & \multicolumn{2}{|c|}{$\begin{array}{c}\text { Bolton stress, } \\
t / \mathrm{m}_{2} 2\end{array}$} & \multirow{2}{*}{$\begin{array}{l}\text { Deflection } \\
\text { mum }\end{array}$} \\
\hline & $S x$ & $\mathrm{Sz}$ & $\mathbf{S x}$ & $\$ x$ & \\
\hline $111-1$ & $\pi \longdiv { 1 , 6 0 9 7 }$ & 0.1293 & 10.5761 & 0.344 & -7.5244 \\
\hline $111-2$ & 0.0712 & $-0.002 t$ & 0.6989 & 0.0102 & $0.346 !$ \\
\hline III-3 & 0,0867 & -0.0028 & 0.6790 & 0.0103 & $0.2010 \mathrm{~S}$ \\
\hline III-4 & 0.0973 & $.0 .003 \mathrm{t}$ & -0.6596 & 10161 & 0.1674 \\
\hline 1145 & $-1,1069$ & 0.157 & 3.3045 & 0.1195 & .2 .5650 \\
\hline $111-6$ & 3.2192 & 0.1194 & 2.3250 & -01182 & -2.0106 \\
\hline \multicolumn{6}{|c|}{ Case IV } \\
\hline & \multicolumn{2}{|c|}{$\begin{array}{c}\text { Top sitess, } \\
\text { t/cinz }\end{array}$} & \multicolumn{2}{|c|}{$\begin{array}{c}\text { Bottou stress } \\
\text { t/cn12 }\end{array}$} & \multirow{2}{*}{$\begin{array}{l}\text { Deflection } \\
\text {,nim }\end{array}$} \\
\hline & $S x$ & $\$ z$ & $\$ x$ & $S x$ & \\
\hline $1 V-1$ & -6033 & $6.721 \mathrm{E} .03$ & 605012 & $+0.1392 ?$ & -4.10575 \\
\hline$\sqrt{1+2}$ & 0.033 & $5.49 \mathrm{E}-1)+4$ & $2.28 \mathrm{E}, 122$ & -549104 & $.124 \mathrm{E} .02$ \\
\hline $\mathrm{I}-3$ & -0.020 & $5,04 E-(1) \cdot 1$ & 2.04102 & $504 \mathrm{E} 04$ & $.9 .20 \mathrm{E} .03$ \\
\hline IVat & -0.019 & $460 \mathrm{G}(1) 4$ & $1 X 6 E-02$ & .4660 .04 & $-3.16 \mathrm{E} 03$ \\
\hline IV-5 & .2 .090 & $7,071 \div 02$ & $2,132 S 1$ & $-7.19 E-02$ & +1.45052 \\
\hline$I V+G$ & -1.635 & $6.0415-62$ & $1.64,947$ & $-7.02 E 02$ & -1.12876 \\
\hline \multicolumn{6}{|c|}{ Cuse $\mathrm{Y}$} \\
\hline & \multicolumn{2}{|c|}{$\begin{array}{l}\text { Top stress, } \\
\text { cent } 2\end{array}$} & \multicolumn{2}{|c|}{$\begin{array}{l}\text { Botlom stress, } \\
\text { } / \operatorname{cm} 2\end{array}$} & Deflection \\
\hline & $\mathbf{S x}$ & $S z$ & $5 x$ & $S x$ & \\
\hline$v-1$ & -5.00345 & $\$ .921 .02$ & 406049 & $-2.411=0124$ & -4.12497 \\
\hline $\mathrm{V.2}$ & -1.721 .02 & $.2 .87 \mathrm{tg}$ & $1,32] \div-02$ & $2.87 \mathrm{f} 05$ & $-1.17 \mathrm{~F}, 02$ \\
\hline$E-3$ & $-1.50 \mathrm{E}-42$ & -3.835 .05 & $1.605-02$ & $7.82 \mathrm{E}-05$ & $-5.64 \mathrm{E}, 03$ \\
\hline$\sqrt{4}$ & -1.385 .02 & $2.71) E 0.0$ & 1331502 & 2.791005 & $-0.6832,03$ \\
\hline 8.5 & $-1,2023$ & $-591 \mathrm{E02}$ & 1,31524 & $-3,23 \mathrm{E} \cdot 1,2$ & $-1 .+5659$ \\
\hline 56 & -1.29026 & $0.11 S 53$ & 1.31217 & $4.98 E .02$ & $-1,15482$ \\
\hline & & & VI & & \\
\hline & $\begin{array}{r}\text { Top } \\
\text { t/o }\end{array}$ & tress & $\begin{array}{r}\text { Bortor } \\
\text { is }\end{array}$ & $\begin{array}{l}\text { stress. } \\
\text { n2 }\end{array}$ & Deflection \\
\hline & Sx & $\$ \%$ & $S x$ & $5 x$ & \\
\hline VI-I & -12.0139 & $0.13,76$ & $12.52+5 !$ & -0.27724 & -8.10336 \\
\hline$V !-2$ & $-23 \mathrm{ME}-\mathrm{N2}$ & $5.40 E-(24$ & 32 SE- 02 & $-5.49 \mathrm{E} \cdot 04$ & $-1.24 \mathrm{E}-02$ \\
\hline VI.3 & $-2,0+\mathrm{E} \cdot 02$ & $5,0+E, 0)$ & $20+1 \mathrm{E} \cdot 62$ & $-5.0+2 \cdot 0.04$ & $-0.20 \mathrm{E}-0.3$ \\
\hline Vl-4 & $-1.865-12$ & G, $6605-04$ & $1.86 E-102$ & $.4 .66 \mathrm{~F}-0.04$ & $-3.16 \mathrm{E} 0 \mathrm{0}$ \\
\hline $11-5$ & $-\sqrt{15569}$ & 0.158512 & 4.240 .57 & $-0.1+284$ & -285306 \\
\hline VI.6 & .3 .34677 & 0.119860 & 3.27414 & .0 .13951 & 42.24066 \\
\hline
\end{tabular}

The relationship between bottom flange stresses ( $\mathrm{Sx}$ ) and web depth to flange width ratio at constant web depth was examined and illustrated in figure (9). From this figure, it can be noted that increasing in web to flange ratio attends to increasing the tension stresses in top flange. In additional using stiffeners leads to decreasing in tension stresses by approximately $20 \%$ in case of beams without prestressing and prestressed beams. In the other hand increasing in web to flange ratio at constant flange width leads to decreasing in tension stresses (Sx) in bottom flange as illustrated in figure (10). In additional in case of using stiffeners leads to decreasing in tension stress by approximately $20 \%$ in each case of simply supported beams and prestressed beams.

In addition, the relationship between bottom flange stresses (Sz) and web depth to flange width ratio at constant flange width was examined and illustrated in figure (11). From this figure, it can be noted that using vertical stiffeners increasing stresses in bottom flange while in the case without stiffeners the stresses tends to be zero. In the other hand increasing in web to flange ratio at constant web depth leads to increasing in compression stresses (Sz) in bottom flange as illustrated in figure (12).

The effect of increasing web depth to flange width ratio at constant web depth on deflections was examined and illustrated in figure (13). From this figure, it can be noted that increasing in web to flange ratio attends to increasing in deflection. In additional using stiffeners leads to the same deflections in the two conditions of beams without prestressing and prestressed beams. In the other hand increasing in web to flange ratio at constant flange width leads to decreasing in deflection as illustrated in figure (14).

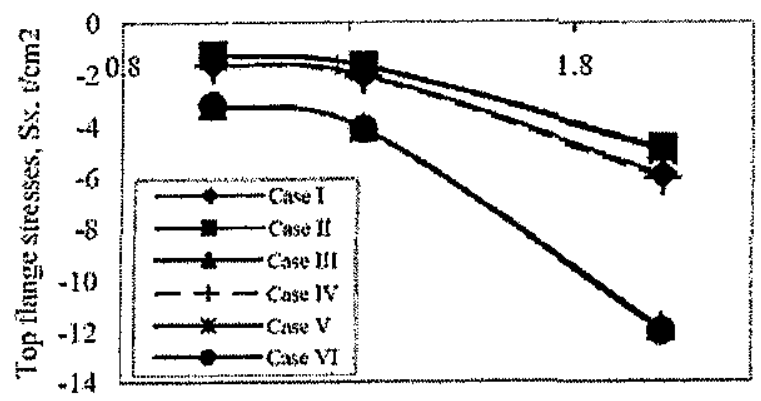

web dejthillange width

Figure (7), top flange stress $S_{x}$ at constant web depth.

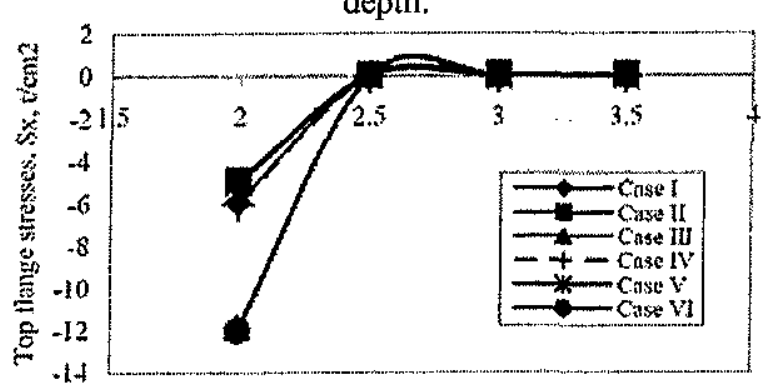

web depthithange width

Figure (8), top flange stress $\mathrm{S}_{\mathrm{x}}$ at constant flange width.. 


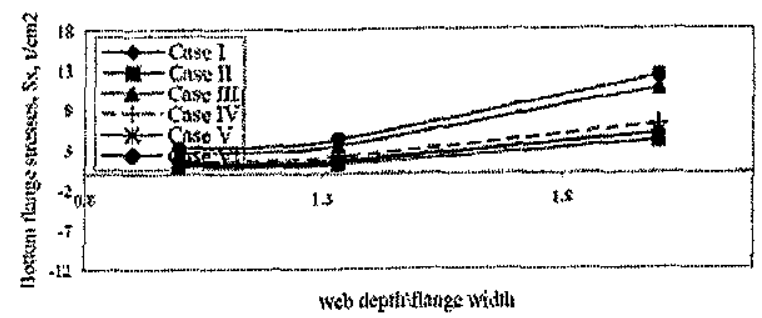

Figure (9), bottom flange stress $S_{x}$ at constant web depth.

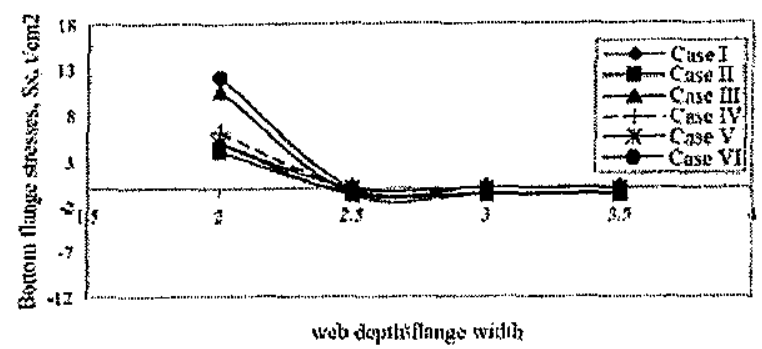

Figure (10), bottom flange stress $S_{x}$ at constant flange width.

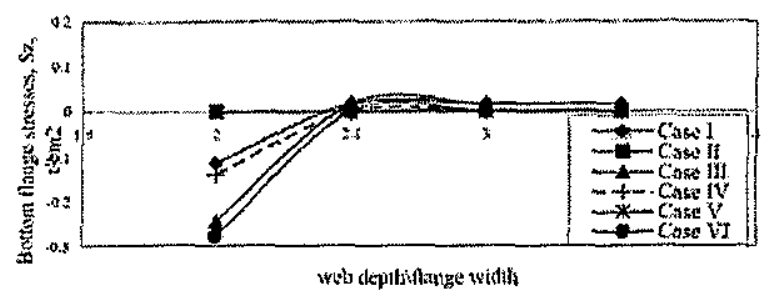

Figure (11), top flange stress $S_{z}$ at constant flange width.

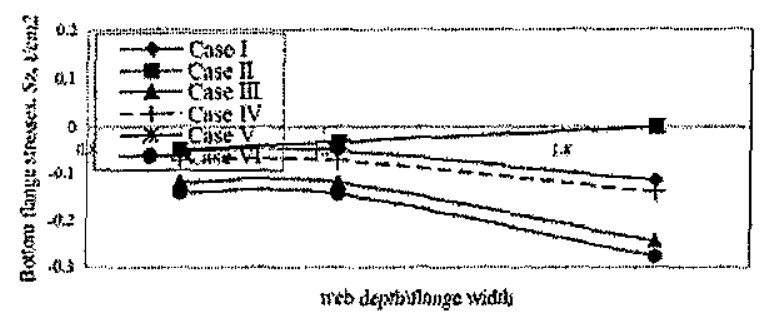

Figure (12), bottom flange stress $S_{z}$ at constant web depth.

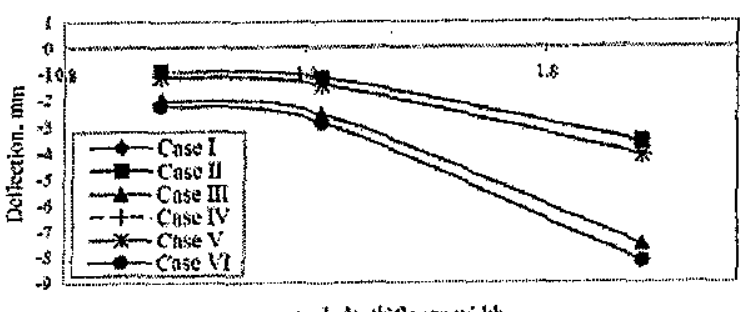

web dicytinlange width

Figure (13), deflection at constant web depth.

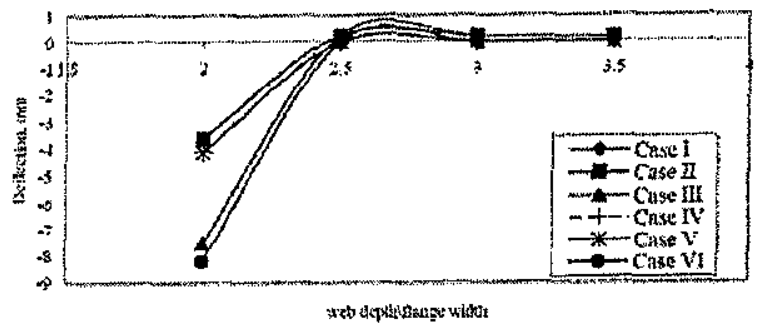

Figure (14), deflection at constant flange width.

\section{CONCLUSION AND RECOMMENDATIONS}

- In case of prestressing, it is better to increase the flange width rather than increase the web depth to improve the stiffiness of the prestressed beams.

- In case of steel beams without prestressing it is better to increase the web depth rather than increase the flange width to improve the stiffness of the beams.

- The exist once of vertical stiffeners increases the stresses while it has not affected the deflection of the beams in both cases of prestressing or nonprestressing.

- It is recommended to study the effect of stiffeners and prestressing under dynamic and fatigue loading.

\section{REFERENCES}

[1] Bottle-holders drive c. (1987), Prestressed reinforced concrete, Hoepli.

[2] Nunziata v. (1997). Theory and practice of the structures in steel, Dario Flaccovio publisher.

[3] Nunziata v. (1999). Structures in steel prestressed, Dario Flaccovio publisher. 